\title{
Research on emergency logistics management based on Intelligent Supply Chain
}

\author{
Yonghui $\mathrm{CAO}^{1, \mathrm{a}}$, He JIANG ${ }^{* 1, \mathrm{~b}}$ \\ ${ }^{1}$ Department of Business Administration, Guangzhou College of Technology and Business, Guangzhou, China \\ * Corresponding author: He JIANG
}

\begin{abstract}
The effective prevention and response of public emergencies such as natural disasters is not only a difficult problem for China, but also a problem that governments all over the world hope to be solved effectively. Emergency supply chain management is very important to disaster relief. It determines whether the emergency work can be carried out efficiently and orderly, which is a major event affecting the national economy and people's livelihood. The theory of intelligent supply chain provides a new research perspective for emergency logistics management. This paper combines the theory of intelligent supply chain with emergency theory, analyzes the necessity of intelligent supply chain in emergency management, and puts forward the construction principles. Finally, the paper puts forward some suggestions based on the intelligent supply chain emergency logistics management.
\end{abstract}

\section{Introduction}

China is a country with vast territory and large population. Public health, human accidents and disasters, social security and other emergencies also occur from time to time. The frequent occurrence of public emergencies will not only cause huge material property losses, but also bring serious threats to people's life, health and safety, which is not conducive to the benign and stable operation of social order. The effective prevention and response of public emergencies such as natural disasters is not only a difficult problem for China, but also a problem that governments all over the world hope to be solved effectively.

In China, the occurrence of natural disasters is very frequent and various, which has brought huge losses to our country. According to statistics, the direct economic losses caused by natural disasters each year exceed 100 billion, and the casualties amount to one million. China has become one of the countries most affected by the disaster. In the process of emergency relief, the damage of infrastructure brings great difficulties to the rescue. Due to the imperfection of emergency supply chain management system, rescue is hindered and the best rescue time is delayed. Therefore, emergency supply chain management is very important for disaster relief. It has a direct impact on whether the government departments can make quick response and command to disasters, and determines whether the emergency work can be carried out efficiently and orderly. It is closely related to the fate of the affected areas and the masses, and is a major event affecting the national economy and people's livelihood. Under the frequent natural disasters, the emergency response ability of governments is severely tested. Emergency management level has become one of the important indicators to evaluate the work of the government.

Taking the basic situation of natural disasters in 2019 issued by the Ministry of emergency management as an example, the disaster situation is shown in Table 1.

Table1. basic situation of natural disasters in China in 2019 released by emergency management department

\begin{tabular}{c|c|c|c|c}
\hline $\begin{array}{c}\text { The total } \\
\text { number of } \\
\text { victims in } \\
\text { the whole } \\
\text { year }\end{array}$ & $\begin{array}{c}\text { Emergency } \\
\text { resettlement }\end{array}$ & $\begin{array}{c}\text { collapse } \\
\text { of the } \\
\text { housing }\end{array}$ & $\begin{array}{c}\text { Affected } \\
\text { area of } \\
\text { crops }\end{array}$ & $\begin{array}{c}\text { Direct } \\
\text { economic } \\
\text { loss }\end{array}$ \\
\hline $\begin{array}{c}130 \\
\text { million } \\
\text { person } \\
\text { times }\end{array}$ & $\begin{array}{c}5.286 \\
\text { million } \\
\text { person times }\end{array}$ & 126000 & $\begin{array}{c}19.2569 \\
\text { million } \\
\text { hectares }\end{array}$ & $\begin{array}{c}327.09 \\
\text { billion } \\
\text { yuan }\end{array}$ \\
\hline
\end{tabular}

The theory of intelligent supply chain provides a new research perspective for emergency logistics management. In today's "big data, big logistics" background, online and offline interconnection has become the general trend. As an important part of emergency management activities, supply chain management is necessary. The Internet promotes the synchronization of information flow and logistics, and improves the operation efficiency of the whole supply chain. Therefore, the combination of intelligent supply chain theory and emergency theory is of great significance to solve the problems in emergency logistics. However, there are few researches on the construction of emergency supply chain system in China. At present, the modern supply chain management is booming, and has gradually become a hot spot of social 
concern. Some emergencies have caused huge casualties and property losses to human society. In the face of these emergencies, our passive situation in response fully exposed the vulnerability of the emergency supply chain. It also puts forward many practical problems to be considered and solved urgently.

\section{Literature review at home and abroad}

\section{1 supply chain emergency logistics}

Most of the existing literature in foreign countries is from the perspective of general emergency logistics, including the construction of emergency logistics, a specific operational link and other issues. For example, akkihal, A.R. studied the impact of inventory on location and route selection under the stochastic demand model based on the characteristics of emergency logistics. Balcik, B. \& beam on, B.M. studied the location of logistics rescue facilities in humanitarian relief. Some scholars combine supply chain theory with emergency logistics to study. This is mainly reflected in the literature of supply chain emergency logistics management and coordination mechanism. Some scholars also put forward that emergency supply chain is a process of effective organization, management and control of emergency materials, information, services and other elements from the supplier to the place of the incident.

There are few domestic literatures on the connotation, type and model construction of emergency logistics system from the perspective of supply chain. Some scholars mainly study the operation model and construction of urban emergency logistics network. Some scholars analyzed the elements and characteristics of emergency logistics system, and further analyzed the construction principles and operating conditions of emergency logistics system. In addition, some researchers study the operation mode of emergency supply chain by establishing various models. For example, some scholars discussed the construction of general operation model of emergency supply chain based on SCOR model. Some scholars combined with other theories to explore the application of emergency supply chain in practice, such as the application of complex network theory in supply chain emergency management, the multi-agent supply chain emergency coordination system structure and coordination mechanism.

\section{2 smart supply chain}

Chung et al. constructed a planning framework for dynamic design and operation of intelligent supply chain[1]. Karimi et al. designed a multi commodity multimodal transportation supply chain network for intelligent manufacturing[2]. Oh et al. studied the attributes of intelligent manufacturing supply chain, and proposed a model to determine the performance of intelligent supply chain[3]. Li et al. built a distributed node deployment model of coastal port intelligent logistics supply chain under cloud computing. The simulation results show that the model can improve the scheduling path optimization and intelligent control ability of coastal port intelligent logistics supply chain[4]. Zhou et al. proposed an intelligent supply chain information system based on Internet of things technology[5]. Ghadimi et al. proposed a multi-agent system method to solve the sustainable supplier evaluation and selection process[6].

Domestic scholars' research on the construction of smart supply chain mainly includes theory, empirical study and case study. Cai Jin pointed out that the concept of supply chain innovation is inclusiveness and openness[7]. The key is integration and optimization, the core is coordination. The goal is mutual benefit and winwin, the direction is intelligent and intelligent, and the essence is value creation. For example, based on the background of the new era, aiming at the development mode of agricultural product supply chain integration and intellectualization, Zhao Zhenqiang constructed a new agricultural product intelligent supply chain system framework from the construction of information sharing platform[8]. Based on the internal relationship between the Internet of things and the supply chain, some scholars put forward the idea of intelligent supply chain platform construction. Some scholars put forward the construction of smart supply chain system from the aspects of intelligent strategy, intelligent supply chain platform and supply chain early warning. Some people also proposed to build the smart supply chain system from the business, technology and management modules. In the aspect of empirical research, some scholars have discussed the performance evaluation of smart supply chain, and some scholars have discussed the innovation and application of smart supply chain combined with cases.

\section{Necessity analysis and construction principle of intelligent supply chain in emergency management}

\section{1 smart supply chain can meet many management needs in emergency management}

First, it can meet the comprehensive requirements of emergency management. Emergencies can have a significant impact on society and enterprises. For enterprises, the light impact is to increase the operating cost of enterprises, and the heavy impact will cause the business system paralysis, even delisting. For the society, it can affect the stability of the masses and live and work in peace and contentment. The stability and reliability of supply chain logistics activities become the key factors of supply chain operation success or failure. Intelligent supply chain is driven by the demand of emergency management, and is an extended end-to-end supply chain operation driven by terminal demand planning. Smart supply chain emphasizes information sharing and interaction with upstream and downstream organizations. It really realizes the formation of demand plan through demand perception. Focus on horizontal process end-toend integration, and on this basis, it forms an intelligent supply chain. The introduction of smart supply chain into emergency management can meet the comprehensive 
requirements of emergency management, which is the whole supply chain thinking. The thinking mode of smart supply chain must be from point to area, emphasizing the overall situation.

Second, it meets the requirements of the coordination of emergency management. Generally speaking, the efficient operation of traditional supply chain is inseparable from the leading role of its core enterprises. They are linked by economic interests and bound by contracts. This is the mobilization and coordination of the whole supply chain by the core enterprises. The core organization of emergency supply chain should be undertaken by government agencies. Its establishment and even the control of the whole supply chain are endowed by laws and regulations and administrative power. The main body of emergency logistics is multi-party, including the owners, users and recipients of emergency logistics resources, such as the government, suppliers, storage, transportation, victims, etc. Their participation behavior refers to that the participants have different limited and dynamic goals before and after the crisis scenario of public emergencies because of their different positions, starting points, constraints and environmental factors. They then show different reactions and decision-making behaviors. The intelligent supply chain can coordinate the will of all parties in emergency management to meet the requirements of coordination.

Third, it can meet the time requirement of emergency management. Emergency management emphasizes the value of time, and response speed has become an important factor affecting the effectiveness of emergency management and value creation ability. Interference factors destroy the normal operation of the supply chain, which will inevitably lead to the decline of response speed. If the members of each organization in emergency management can return to normal operation in a shorter period of time, it can not only timely deal with the emerging risks, but also curb the momentum of risk extension. Smart supply chain has unique advantages in time requirement, which is also the embodiment of its sensitivity.

Fourth, it can meet the emergency management requirements. Emergency management deals with catastrophic events with uncertain time, location and disturbance degree. This is the sudden nature of emergency management. The suddenness determines the suddenness and diversity of emergency logistics activities in supply chain. This objectively requires the supply chain emergency logistics system to have high system flexibility, in order to implement personalized solutions for different abnormal situations and minimize disturbance. Smart supply chain has good flexibility and dynamic, and can deal with emergencies timely and accurately.

\section{2 construction principles of emergency logistics system based on Intelligent Supply Chain}

First, it is the principle of unified command. The rescue process of sudden natural disasters often involves many fields and departments. If there is no unified command in a short period of time, it will lead to operational confusion. If each department does its own work, it will cause unnecessary waste of time and resources. There should be a unified command center in the system, so as to make timely response and command all departments to carry out rescue. Due to the particularity of emergency management the command center should be an administrative department of the government.

Second, it is the principle of broad participation and collaborative operation. Although the government plays a leading role in the emergency process, the successful emergency management cannot do without the cooperation and support of the broad masses of people and groups. To give full play to these forces, it is necessary for the government to carry out coordinated management in an organized way, so that they can complement each other with the government operation and carry out emergency rescue work more efficiently.

Third, it is the dynamic principle. In the process of emergency rescue, the demand and supply of emergency materials cannot be predicted. The occurrence of secondary disasters may also lead to other disasters. These uncertain factors determine that the design of emergency supply chain must have certain flexibility, so as to respond in time with the change of demand.

\section{Emergency logistics management and suggestions based on Intelligent Supply Chain}

\section{1 strengthen the logistics management of smart supply chain and enhance the construction of emergency support force}

Emergency intelligent supply chain management requires to strengthen the construction of modular emergency support force. Emergency support force is the basis of emergency support, and also an important node in the emergency supply chain, which can directly provide terminal support for emergency support demand units and individuals. In the future, the emergency support force will gradually develop in the direction of miniaturization, establishment synthesis and function integration. Taking modular organization as the basic idea, the composition of emergency support force will be optimized, so that the emergency support force can become an organic whole composed of several emergency support units which can independently complete the specified functions and are closely connected with each other. When an emergency event occurs, it can be flexibly used and combined according to the needs of emergency, give full play to its professional advantages, implement rapid and efficient support for the units and individuals in need of emergency support, realize the transformation from "quantity type" to "speed type", and achieve the dynamic balance between security benefit and security efficiency. 


\section{2 build an intelligent emergency management platform and improve the emergency information sharing mechanism of the supply chain}

In emergency management, the timely and comprehensive transmission of information is the premise of correct decision-making and the important guarantee of rapid response of the system. In the emergency management of Japan and the United States, the advanced ideas and technical means of modern supply chain management are fully applied to realize the rapid collection and transmission of information. In China, we apply advanced information and communication technology to build a perfect emergency information platform, so as to realize the information communication with the disaster area in the case of infrastructure damage. It is very important to realize the real-time transmission and management of information. It can be said that full and accurate information flow is the premise and foundation for smooth supply chain. The operation of smart supply chain has higher requirements for information circulation. At present, China's enterprises pay less attention to information circulation and supply chain intelligence is low. This restricts the information sharing and information circulation among the supply chain node enterprises. Enterprises must formulate a scientific strategic development plan of smart supply chain. Through information sharing and integration, enterprises complete the analysis, optimization and collaboration of intelligent supply chain process, broaden enterprise information communication channels, form seamless connection between partners, and improve the optimization and collaborative management level of intelligent supply chain. At the same time, the necessary risk prevention mechanism and benefit distribution mechanism should be established. The principle of risk sharing and benefit sharing should be followed among partners. Only by ensuring the information security of partners, partners are willing to share their own unique information to ensure the orderly development of smart supply chain alliance.

In short, through the intelligent supply chain information platform, we can timely update the geographical conditions of the disaster area and surrounding areas, and minimize the transportation obstacles caused by road damage.

\subsection{Improve the emergency material reserve system and improve the efficiency of material preparation}

Aiming at the problem of insufficient material reserve and uneven distribution in China, the enterprise dynamic alliance is established to solve the problem. Using the enterprise alliance method of supply chain management for reference, the government can establish alliance relationship with some enterprises after screening. These enterprises are used as dynamic warehouses in peacetime to help the government to reserve some disaster relief materials while conducting commercial operations. In this way, the government has reduced the fixed costs, and because of the commercial operation of enterprises, the relief materials can be kept in a state of frequent renewal, avoiding the danger caused by the failure of materials, and reducing the cost of dealing with the obsolete materials. In the state of emergency, these enterprises can be transformed into suppliers of government emergency procurement in time, improve the efficiency of material preparation, and effectively reduce transaction costs.

\subsection{Establish emergency logistics safety supervision mechanism based on Supply Chain}

According to the process control of emergency logistics, the emergency logistics safety supervision system of intelligent supply chain is established. The main responsibilities of the emergency command center are to analyze the emergency material demand, formulate the emergency logistics plan, formulate the coordination and guarantee plan, comprehensively dispatch the emergency logistics, and collect the information of material supply and demand. The nodes of emergency logistics mainly include the material reserve warehouse, emergency distribution center, rescue center, rescue point and so on. The logistics node is mainly responsible for the management of purchasing management, warehousing management, transportation management and distribution management. Emergency logistics information system can be regarded as the central nervous system of the whole emergency logistics process, which runs through all links. Its main functions include storing emergency resources, conducting real-time dynamic monitoring, developing and processing business in various stages, assisting management decision-making and basic database.

The safety supervision of emergency logistics based on supply chain has reversed the problem that only positive logistics was paid attention to in the emergency logistics operation in the past, and the reverse logistics was not paid enough attention to. Because the operation system of the supply chain is bidirectional, a good logistics process must be the unity of positive and reverse. In the event of an emergency, not only a large number of necessary materials need to be transported to the disaster area quickly, but also the damaged materials need to be transported out from the disaster area. As most emergencies are unpredictable, many standing materials may have expired before they are used. Reverse recovery and repair can reduce the production time and inventory level of new inventory materials. Once the emergency occurs, it can greatly shorten the supply time, improve the operation efficiency of the whole emergency logistics system, and better achieve its security objectives.

\section{Conclusion}

How to effectively prevent and respond to public emergencies such as natural disasters is a difficult problem that governments all over the world, including China, hope to be effectively solved. By combing the relevant research context, this paper summarizes the main problems existing in emergency logistics management in China, analyzes the necessity and construction principles of intelligent supply chain in emergency management, and puts forward the emergency logistics management system 
based on the perspective of intelligent supply chain, so as to provide theoretical support for emergency management.

\section{Acknowledgment}

This work is financially supported by outstanding scholars of philosophy and Social Sciences in Henan Province higher education in 2018, 2018-YXXZ-06; Henan philosophy and Social Sciences Planning Project in 2019, 2019BJJ003; The social development project of Henan provincial key R \& D and promotion project (Science and technology tackling key problems) in 2019, project number: 515; The science and technology innovation talent support program project of Henan Province higher education (HUMANITIES AND SOCIAL SCIENCES) in 2017, 2017-cxrc-004; Foshan social science planning project in 2020, 2020-QN11. Thanks for the help.

\section{References}

1. CHUNG B D, KIM S I, LEE J S. Dynamic supply chain design and operations plan for connected smart factories with additive manufacturing [J]. Applied sciences, 2018, 8 (4) : 583 - 598.

2. KARIMI B, BASHIRI M. Designing a multicommodity multimodal splittable supply chain network by logistic hubs for intelligent manufacturing [J]. Procedia manufacturing, 2018, 17,1058 - 1064.

3. OH, JEONG B. Tactical supply planning in smart manufacturing supply chain [J]. Robotics and computer-integrated manufacturing, 2019, 55: 217 233.

4. LI S H, SUN Q B, WU W L. Benefit distribution method of coastal port intelligent logistics supply chain under cloud computing [J]. Journal of coastal research, 2019, 93: 1041 - 1046.

5. ZHOU Y S, XU X J. Intelligent supply chain information system based on internet of things technology under asymmetric information $[\mathrm{J}]$. Symmetry, 2019, 11 ( 5) : 656.

6. GHADIMI P, WANG C, LIM M K, et al. Intelligent sustainable supplier selection using multi - agent technology: theory and application for industry 4.0 supply chains $[\mathrm{J}]$. Computers \& industrial engineering, 2019, 127: 588 - 600 .

7. Cai Jin. Grasping the essential characteristics of supply chain innovation [N]. Modern logistics news, March 8, 2017 (A6)

8. Zhao Zhenqiang, Zhang Litao, Hu Zibo. Construction and operation mode of agricultural products intelligent supply chain in the new technology era [J]. Commercial economy research, 2019 (11): 132-135. 